\title{
HUBUNGAN ASUPAN ZAT GIZI MAKRO DAN PROFIL LIPID DENGAN KEJADIAN PENYAKIT JANTUNG KORONER PADA PASIEN LANSIA DI RUMAH SAKIT ISLAM JEMURSARI SURABAYA
}

\author{
Relationship between Macronutrient Intake and Lipid Profiles with Coronary Heart Diseases of \\ Elderly Patient at Jemursari Islamic General Hospital, Surabaya \\ Hadiar Huriyah Rahma1, R. Bambang Wirjatmadi² \\ ${ }^{1}$ Program Studi S1 Kesehatan Masyarakat, Fakultas Kesehatan Masyarakat, Universitas Airlangga, Surabaya \\ ${ }^{2}$ Departemen Gizi Kesehatan, Fakultas Kesehatan Masyarakat, Universitas Airlangga, Surabaya \\ Email: hadiarachma@gmail.com
}

\begin{abstract}
ABSTRAK
Penyakit jantung koroner merupakan kondisi seseorang yang mengalami penyumbatan di pembuluh darah jantung akibat penumpukan plak. Salah satu faktor terjadinya penyakit jantung koroner adalah pola konsumsi pangan yang kurang baik sehingga meningkatkan kadar lemak di dalam tubuh. Hal ini menyebabkan asupan gizi yang masuk ke dalam jantung tidak maksimal. Tujuan penelitian ini adalah untuk mengetahui hubungan antara pola konsumsi pangan kejadian penyakit jantung koroner pada pasien dislipidemia lansia di Rumah Sakit Islam Jemursari Surabaya. Penelitian ini menggunakan desain penelitian case control dengan total responden sebanyak 20 kelompok kasus dengan riwayat PJK dan 20 kelompok kontrol dengan dislipidemia di Poli Penyakit Dalam RSI Jemursari. Uji analisis pada penelitian ini menggunakan uji chi square. Variabel yang diteliti adalah asupan karbohidrat, lemak, frekuensi makan, kadar kolesterol total, kadar Low-Density Lipoprotein (LDL), dan kadar trigliserida. Hasil penelitian menyatakan terdapat hubungan asupan lemak dengan kejadian penyakit jantung koroner $(\mathrm{p}=0,002 ; \mathrm{OR}=13,500 ; 95 \% \mathrm{CI})$, dan tidak terdapat hubungan asupan gizi karbohidrat $(\mathrm{p}=0,105)$, frekuensi makan $(\mathrm{p}=0,451)$, kadar kolesterol total $(\mathrm{p}=0,237)$, kadar LowDensity Lipoprotein (LDL) $(\mathrm{p}=0,054)$, dan kadar trigliserida $(\mathrm{p}=0,341)$ dengan penyakit jantung koroner. Diharapkan menjaga kestabilan asupan gizi terutama asupan lemak untuk menurunkan peluang terjadinya PJK.
\end{abstract}

Kata kunci: asupan makronutrient, penyakit jantung koroner, profil lipid

\begin{abstract}
Coronary Heart Disease (CHD) is a condition where plaque build up inside the coronary artery which could lead to heart attack. One of the factors that affects CHD is food consumption pattern that can increase lipid level so the heart could not get any nutrition optimally. The research was aimed to analyze the relationship between food consumption pattern, and lipid profile with CHD in elderly patients of Jemursari Islamic General Hospital, Surabaya. The study was a case control design with 20 of case patients who had CHD history and 20 of control patients with dyslipidemia. The analysis used chi square test for the variables such as carbohydrates and fat intake, meal frequency, total cholesterol level, Low Density Lipoprotein (LDL), and triglycerides level. The result showed that there is relationship between fat intake and CHD ( $p=0.002 ; O R=13.500 ; 95 \% C I)$, but there were no relationship between carbohydrates intake ( $p$ $=0.105)$, meal frequency $(p=0.451)$, total cholesterol level $(p=0.237)$, Low-Density Lipoprotein $(L D L)(p=0.054)$, and triglycerides level $(p=0.341)$, with CHD in dyslipidemia elderly patient. Elderly patients is expected to maintain their nutrient intake, especially fat intake in order to reduce the chance of CHD.
\end{abstract}

Keywords: macronutrient intake, coronary heart disease, lipid profile

\section{PENDAHULUAN}

Penyakit Jantung Koroner (PJK) menjadi salah satu penyebab kematian tertinggi di Indonesia sebesar $45 \%$ dan sebanyak $2 \%$ PJK terjadi pada usia lansia yaitu 65 sampai 74 tahun (Kementerian Kesehatan, 2013). Penyakit jantung koroner adalah keadaan dimana pembuluh darah jantung yang seharusnya membawa sel darah merah dan nutrisi lain tersumbat oleh kolesterol yang berlebihan sehingga terjadi penumpukan plak di dinding pembuluh darah. Sel darah merah tersebut diperlukan oleh jaringan tubuh manusia sebagai pembawa oksigen agar kinerja jantung dapat maksimal (Adriani dan Wirjatmadi, 2012). 
Menurut Kusuma, et al. (2015), salah satu faktor penyebab terjadinya PJK adalah asupan konsumsi seseorang yang mengandung banyak lemak. Lemak yang dikonsumsi mengandung banyak kolesterol dan trigliserida yang menjadi salah satu komponen kadar lemak dalam darah yang dapat menyebabkan penyakit jantung koroner (Fathila, et al., 2015). Dalam penelitian ini, peneliti ingin melihat bagaimana pola konsumsi pada pasien dislipidemia yang menderita penyakit jantung koroner di usia lansia. Tujuan penelitian ini untuk mengetahui hubungan antara pola konsumsi pangan dengan kejadian penyakit jantung koroner pada pasien dislipidemia lansia di Rumah Sakit Islam Jemursari Surabaya.

\section{METODE}

Jenis penelitian menggunakan penelitian observasional analitik dengan rancang bangun penelitian case control. Populasi kasus dalam penelitian ini adalah pasien Penyakit Jantung Koroner dan populasi kontrol adalah pasien dislipidemia Rumah Sakit Islam Jemursari Surabaya dengan kriteria inklusi pria dan wanita yang berusia 60-74 tahun dan telah melakukan pemeriksaan kadar profil lipid. Cara pengambilan sampel dengan simple random sampling. Pengambilan data dengan cara wawancara kuesioner, 24 hours food recall, dan data rekam medis yang selanjutnya akan dianalisis menggunakan uji Chi Square. Jumlah sampel yang diambil adalah masing-masing sebanyak 20 responden kelompok kasus dan kelompok kontrol.

Penelitian ini melewati uji etik dari Komisi Etik Penelitian Kesehatan Fakultas Kesehatan Masyarakat Universitas Airlangga No. 125-KEPK.

\section{HASIL DAN PEMBAHASAN}

Karakteristik responden yang diambil dalam penelitian ini, baik pada kelompok kasus maupun kontrol yaitu jenis kelamin, usia, pendidikan terakhir, dan pendapatan. Variabel lain yang diteliti adalah pola konsumsi pangan yang meliputi asupan kabohidrat dan lemak, frekuensi makan, serta profil lipid yang meliputi kadar kolesterol total, kadar
LDL, dan kadar trigliserida. Tabel 1. menunjukkan distribusi jenis kelamin pada kelompok kasus dan kelompok kontrol sebagian besar berjenis kelamin pria. Hasil distribusi usia yaitu sebagian besar kelompok kasus dan kontrol pasien berusia 60-67 tahun. Usia tersebut termasuk dalam kategori lanjut usia (lansia). Pendidikan terakhir responden menunjukkan hasil distribusi pendidikan pada kelompok kasus memiliki pendidikan terakhir paling banyak pada perguruan tinggi dan kelompok kontrol SMA.

Tabel 1. Distribusi Jenis Kelamin, Usia, Pendidikan, dan Pendapatan Responden

\begin{tabular}{lrrrr}
\hline \multirow{2}{*}{ Karakteristik } & \multicolumn{4}{c}{ Diagnosa PJK } \\
\cline { 2 - 5 } & \multicolumn{2}{c}{ Kasus } & \multicolumn{2}{c}{ Kontrol } \\
\cline { 2 - 5 } Jenis Kelamin & & & \multicolumn{1}{c}{$\mathbf{n}$} & $\%$ \\
$\quad$ Laki-laki & 11 & 55,0 & 12 & 60,0 \\
$\quad$ Perempuan & 9 & 45,0 & 8 & 40,0 \\
Usia & & & & \\
60-67 tahun & 13 & 65,0 & 12 & 60,0 \\
68-74 tahun & 7 & 35,0 & 8 & 40,0 \\
Pendidikan & & & & \\
Tidak sekolah & 1 & 5,0 & 0 & 0,0 \\
SD & 0 & 0,0 & 1 & 5,0 \\
SMP & 0 & 0,0 & 2 & 10,0 \\
SMA & 9 & 45,0 & 12 & 60,0 \\
Perguruan Tinggi & 10 & 50,0 & 5 & 25,0 \\
Pendapatan & & & & \\
< Rp. 3.045.000 & 14 & 70,0 & 11 & 55,0 \\
> Rp. 3.045.000 & 6 & 30,0 & 9 & 45,0 \\
\hline
\end{tabular}

Sebagian besar pada kedua kelompok memiliki pendapatan di bawah Rp. 3.045.000 setiap bulannya. Menurut Pergub Jatim Nomor 68 Tahun 2015 Tentang Upah Minimum Kabupaten/Kota di Jawa Timur Tahun 2016 batas rendah pendapatan untuk Kota Surabaya adalah Rp. 3.045.000, sehingga menurut distribusi hasil penelitian pendapatan pada responden yaitu memiliki pendapatan yang tergolong rendah (Pemerintah Gubernur Jawa Timur, 2015).

Hasil distribusi asupan zat gizi karbohidrat menunjukkan bahwa $45 \%$ responden pada kelompok kasus mengonsumsi karbohidrat $>60 \%$. Pada kelompok kontrol dimana konsumsi 
karbohidrat $>60 \%$ lebih banyak yaitu sebesar $75 \%$. Namun, tidak ditemukan adanya perbedaan asupan karbohidrat yang signifikan pada kelompok kasus dan kontrol.

Tabel 2. Distribusi Asupan Karbohidrat, Lemak, dan Frekuensi Makan Responden

\begin{tabular}{|c|c|c|c|c|c|}
\hline \multirow{3}{*}{ Zat Gizi } & \multicolumn{4}{|c|}{ Diagnosa PJK } & \multirow{3}{*}{$\mathbf{p}$} \\
\hline & \multicolumn{2}{|c|}{ Kasus } & \multicolumn{2}{|c|}{ Kontrol } & \\
\hline & n & $(\%)$ & $\mathbf{n}$ & $(\%)$ & \\
\hline \multicolumn{6}{|l|}{ Karbohidrat } \\
\hline $50-60 \%$ & 11 & 55,0 & 5 & 25,0 & \multirow{2}{*}{0,105} \\
\hline$>60 \%$ & 9 & 45,0 & 15 & 75,0 & \\
\hline \multicolumn{6}{|l|}{ Lemak } \\
\hline $25-30 \%$ & 12 & 60,0 & 12 & 60,0 & \multirow{2}{*}{0,002} \\
\hline$>30 \%$ & 8 & 40,0 & 8 & 40,0 & \\
\hline \multicolumn{6}{|l|}{ Frekuensi Makan } \\
\hline 1-2 kali makan/hari & 6 & 30,0 & 3 & 15,0 & \multirow{2}{*}{0,451} \\
\hline 3->3kali makan/hari & 14 & 70,0 & 17 & 85,0 & \\
\hline
\end{tabular}

Uji statistik menunjukkan tidak ada hubungan antara asupan zat gizi karbohidrat dengan kejadian penyakit jantung koroner dengan nilai $\mathrm{p}=0,105$. Hal tersebut sejalan dengan penelitian Aswin, et al. (2012) dimana tidak ditemukan adanya hubungan antara asupan karbohidrat dengan kejadian penyakit jantung koroner.

Sumber bahan makanan utama manusia adalah karbohidrat. Zat gizi ini memiliki beberapa fungsi yaitu sebagai sumber energi dan dapat menjalankan beberapa fungsi tubuh manusia (Fatmah, 2010). Dalam satu hari, manusia membutuhkan 50-60\% asupan karbohdirat (Samour, 2013). Menurut Yuliani, et al. (2014), asupan zat gizi karbohidrat yang berlebihan dapat meningkatkan kadar glukosa di dalam darah dan menyebabkan diabetes mellitus yang merupakan salah satu faktor penyebab terjadinya penyakit jantung koroner.

Hasil distribusi asupan zat gizi lemak menunjukkan bahwa $60 \%$ responden pada kelompok kasus mengonsumsi lemak pada batas baik (25-30\%). Pada kelompok kontrol $40 \%$ responden memiliki asupan lemak $>30 \%$. Analisis lebih lanjut menemukan adanya hubungan yang signifikan antara asupan lemak dengan kejadian PJK pada kelompok kasus dan kontrol dengan $\mathrm{p}=0,002$.
Hasil penelitian menunjukkan bahwa ada hubungan antara asupan zat gizi lemak dengan kejadian penyakit jantung koroner dengan nilai $\mathrm{p}=0,002$. Hasil dari odd ratio $(\mathrm{OR}=13.500)$ tersebut sejalan dengan penelitian Putri (2016) yang menyatakan bahwa terdapat hubungan kadar lemak dengan kejadian penyakit jantung koroner.

Asupan lemak yang berlebihan dapat membawa dampak buruk bagi kesehatan, karena dapat meningkatkan kadar lemak yang ada di dalam darah sehingga dapat menyebabkan penyakit jantung koroner (Fathila, et al., 2015). Kadar lemak yang berlebihan mengakibatkan terjadinya penimbunan lemak di sekitar pembuluh darah jantung, sehingga terjadi penyumbatan dan sel darah merah yang membawa oksigen untuk jantung menjadi berkurang.

Berdasarkan variabel frekuensi makan, ditemukan sebesar $70 \%$ pada kelompok kontrol memiliki frekuensi makan sebanyak minimal $3 \mathrm{x} /$ hari. Hasil yang sama terlihat pada $85 \%$ kelompok kasus, tidak ditemukan adanya hubungan yang signifikan antara kedua variabel tersebut.

Hasil wawancara menunjukkan bahwa pasien Rumah Sakit Islam Jemursari Surabaya paling sering mengonsumsi nasi putih sebagai sumber karbohidrat. Kelompok sumber lemak yang paling banyak dikonsumsi adalah ayam, telur, ikan dan susu, sedangkan pada kelompok makanan sumber lemak nabati adalah minyak kelapa yang paling sering digunakan untuk memasak.

Kadar profil lipid dalam darah merupakan salah satu indikator diagnosa penyakit jantung koroner. Kadar profil lipid seperti kolesterol total, LDL, dan trigliserida yang berlebihan dapat menyebabkan penyakit jantung koroner. Kadar kolesterol yang melebihi $>250 \mathrm{mg} / \mathrm{dl}$, kadar LDL yang lebih dari $160 \mathrm{mg} / \mathrm{dL}$ dan kadar trigliserida antara 200-499 mg/dL dapat meningkatkan risiko penyakit jantung koroner (Waloya, 2013; Fatmah, 2010; Freeman dan Junge, 2008).

Hasil analisis menunjukkan hiperkolesterolemia (kolesterol total $>250 \mathrm{mg} / \mathrm{dL}$ ) dialami oleh $15 \%$ responden kelompok kasus dan $35 \%$ responden kelompok kontrol (Tabel 3). Tidak terdapat hubungan yang signifikan antara kolesterol total dan kejadian PJK $(\mathrm{p}=0,237)$. Berdasarkan jenis fraksi lipid, ditemukan proporsi peningkatan 
kadar LDL dan trigliserida yang lebih tinggi pada kelompok kontrol (berturut-turut $60 \%$ dan 55\%). Uji statistik menunjukkan tidak terdapat hubungan antara kedua variabel ini dengan kejadian PJK (berturut-turut $\mathrm{p}$ value $=0,054$ dan 0,341). Menurut keterangan responden, kadar kolesterol yang cukup stabil disebabkan oleh konsumsi rutin obat yang diberikan oleh dokter dan menaati diet jantung yang telah dianjurkan. Kolesterol yang ada di dalam darah dapat mengakibatkan penyakit jantung koroner karena plak yang menempel pada dinding pembuluh darah sehingga terjadi penyumbatan (aterosklerosis). Akibatnya, distribusi asupan gizi yang dibawa oleh dari sel darah merah terhambat sehingga jantung tidak bekerja secara maksimal (Adriani dan Wirjatmadi, 2012).

Tabel 3. Distribusi Kadar Kolesterol Total, LDL, dan Trigliserida Responden

\begin{tabular}{llllll}
\hline \multirow{2}{*}{$\begin{array}{c}\text { Kadar Profil } \\
\text { Lipid }\end{array}$} & \multicolumn{2}{c}{ Kasus } & \multicolumn{2}{c}{ Kontrol } & \multirow{2}{*}{ P } \\
\cline { 2 - 4 } & $\mathbf{n}$ & $\mathbf{( \% )}$ & $\mathbf{n}$ & $\mathbf{( \% )}$ & \\
\hline $\begin{array}{l}\text { Kadar Kolesterol } \\
\text { Total }\end{array}$ & & & & & \\
$\quad 200-249 \mathrm{mg} / \mathrm{dl}$ & 17 & 85 & 13 & 65 & \\
$\quad>250 \mathrm{mg} / \mathrm{dl}$ & 3 & 15 & 7 & 35 & 0,237 \\
$\quad$ Kadar LDL & & & & & \\
$\quad 130-159 \mathrm{mg} / \mathrm{dL}$ & 15 & 75 & 8 & 40 & \\
$>160 \mathrm{mg} / \mathrm{dL}$ & 5 & 25 & 12 & 60 & 0,054 \\
Kadar TG & & & & & \\
$\quad 150-199 \mathrm{mg} / \mathrm{dL}$ & 13 & 65 & 9 & 45 & 0,341 \\
$200-499 \mathrm{mg} / \mathrm{dL}$ & 7 & 35 & 11 & 55 & \\
\hline
\end{tabular}

Hasil penelitian sejalan dengan penelitian Aswin, et al. (2012) yang menunjukkan tidak ada hubungan antara kadar LDL dalam darah dengan penyakit jantung koroner. Hasil ini tidak sejalan dengan penelitian Zahrawardani (2013) yang menyatakan faktor utama terjadinya penyakit jantung koroner adalah kadar trigliserida yang ada di dalam pembuluh darah jantung. Penelitian tersebut mengatakan bahwa terdapat hubungan antara kadar trigliserida dalam darah dengan kejadian penyakit jantung koroner. Kadar trigliserida merupakan salah satu faktor yang menyebabkan terjadinya penyakit jantung koroner, semakin tinggi kadar trigliserida dalam darah, peluang terjadinya penyakit jantung koroner semakin tinggi (Iskandar et al., 2017). Kadar trigliserida yang tinggi berisiko diabetes mellitus dan dapat menimbulkan penumpukan plak yang ada di dalam darah sehingga berisiko penyakit jantung koroner.

\section{KESIMPULAN DAN SARAN}

Terdapat hubungan antara asupan lemak dengan kejadian PJK. Kontribusi energi dari lemak lebih tinggi pada kelompok kontrol dibandingkan dengan kelompok kasus. Tidak terdapat hubungan antara asupan karbohidrat frekuensi makan dan profil lipid dengan kejadian PJK.

Menjaga keseimbangan diet khususnya proporsi asupan energi dari lemak perlu dilakukan oleh penderita PJK untuk menjaga kestabilan lemak darah. Kepatuhan diet penyakit jantung yang baik, menjaga kebugaran tubuh, dan selalu memantau kesehatan diri sendiri perlu dilakukan oleh responden.

\section{DAFTAR PUSTAKA}

Adriani, M. \& Wirjatmadi, B. (2012). Pengantar gizi masyarakat. Jakarta: Kencana Prenada Media Group.

Aswin, A.A.G.A., Kholidah, D., \& Basuki, R. (2012). Profil lipid dan resiko kejadian penyakit jantung koroner (PJK) pada wanita menopouse di Kota Malang (lipid profile and coronary heart disease risk of menopouse women in Malang). Jurnal IKESMA, 8(2), 78-89. Diakses dari https://jurnal.unej.ac.id/index.php/IKESMA/ article/view/1058/872.

Fathila, L, Edward, Z, \& Rasyid, R. (2015). Gambaran profil lipid pada pasien infark miokard akut di RSUP M. Djamil Padang periode 1 Januari 2011-31 Desember 2012. Jurnal Kesehatan Andalas, 4(2), 513-518.

Fatmah. (2010). Gizi usia lanjut. Jakarta: Erlangga.

Freeman, M.W. \& Junge, C. (2008). Kolesterol rendah jantung sehat. Jakarta: Bhuana Iimu Populer.

Iskandar, Hadi, A. \& Alfridsyah. (2017). Faktor risiko terjadinya penyakit jantung koroner pada pasien Rumah Sakit Umum Meuraxa Banda Aceh (Risk factors of coronary heart disease in Meuraxa hospital of Banda Aceh). Jurnal AcTion: Aceh Nutrition Journal, 2(1): 32-42. 
Diakses dari ejournal.poltekkesaceh.ac.id/ index.php/an/article/download/34/29.

Kementerian Kesehatan RI. (2013). Situasi kesehatan jantung. Jakarta: Kementerian Kesehatan RI. Diakses dari http://www.depkes. go.id.

Kusuma, I.M., Haffidudin, M. \& Prabowo, A. (2015). Hubungan pola makan dengan peningkatan Kadar kolesterol pada lansia di Jebres Surakarta. Jurnal Keperawatan, 2(2). Diakses dari https://jurnal.akper17.ac.id/index. php/JK17/article/view/30.

Pemerintah Gubernur Jawa Timur. (2015). Peraturan Gubernur Jawa Timur Nomor 68 Tahun 2015 tentang upah minimum kabupaten/kota di Jawa Timur Tahun 2016. Jawa Timur: Pemerintah Gubernur Jawa Timur.

Putri, N.I. (2016). Hubungan asupan serat dan lemak total dengan kadar kolesterol total pada anggota polisi Polres Rembang. Diakses dari http://eprints.ums.ac.id/47412/1/02.\%20 NASKAH\%20PUBLIKASI.pdf.
Samour, P.Q. (2013). Pediatric nutrition 4th edition. Canada: Jones and Bartlett Learning.

Waloya, T., Rimbawan, \& Andarwulan, N. (2013). Hubungan antara konsumsi pangan dan aktifitas fisik dengan kadar kolesterol darah pria dan wanita dewasa di Bogor. Jurnal Gizi dan Pangan, 8(1), 9-16. Diakses dari http:// journal.ipb.ac.id/index.php/jgizipangan/article/ view/7243/5659.

Yuliani, F., Oenzil, F. \& Iryani, D. (2014). Hubungan berbagai faktor risiko terhadap kejadian penyakit jantung koroner pada penderita diabetes melitus tipe 2. Jurnal Kesehatan Andalas, 3(1), 37-40. Diakses dari http://jurnal.fk.unand.ac.id/index. $\mathrm{php} / \mathrm{jka} /$ article/view/22/17.

Zahrawardani, D., Herlambang, K.S., \& Anggreheny, H.D. (2013). Analisis faktor risiko kejadian penyakit jantung koroner di RSUP Dr. Kariadi Semarang. Jurnal Kedokteran, 1(3), 37-40. 